\title{
Selection for morphology, gaits and functional traits in Lusitano horses: II. Fixed effects, genetic trends and selection in retrospect
}

\author{
A.A. Vicente ${ }^{\mathrm{a}, \mathrm{b}, \mathrm{c}}$, N. Carolino ${ }^{\mathrm{b}, \mathrm{d}}$, J. Ralão-Duarte ${ }^{\mathrm{e}}$, L.T. Gama ${ }^{\mathrm{c}, *}$ \\ a Escola Superior Agrária do Instituto Politécnico de Santarém, Apartado 310, 2001-904 Santarém, Portugal \\ ${ }^{\mathrm{b}}$ Unidade Estratégica de Investigação e Serviços de Biotecnologia e Recursos Genéticos, INIAV, IP 2005-048 Vale de Santarém, Portugal \\ c CIISA - Faculdade de Medicina Veterinária, Universidade de Lisboa, 1300-477 Lisboa, Portugal \\ 'Escola Universitária Vasco da Gama, Estrada da Conraria, 3040-714 Coimbra, Portugal \\ e Associação Portuguesa de Criadores do Cavalo Puro-sangue Lusitano - APSL, Av. Mem Ramires, 94, 2765-337 Estoril, Portugal
}

\section{A R T I C L E I N F O}

Keywords:

Inbreeding depression

Selection intensity

Estimated breeding values

Dressage

Working equitation

\begin{abstract}
A B S T R A C T
Mixed model procedures were used to analyze morphology and gaits records collected in about 18,000 Lusitano horses from 900 studs, over a period of 43 years, and functional records collected since 1998, to carry-out a critical assessment of the fixed effects and selection practices followed in this breed. Fixed effects considered in the analysis of morphology (head/ neck, shoulder/withers, chest/thorax, back/loin, croup, legs and overall impression), gaits and final score (computed by summing partial morphological and gaits scores) were stud, year, sex, inbreeding and age. Functional traits analyzed were the scores obtained in working equitation dressage (WEDT) and maneability (WEMT) trials and in classical dressage (CD), where fixed effects were event, level of competition, sex, inbreeding and age. Phenotypic trends were moderate over the period analyzed, with a slight increase in height at withers, and a decline in final score. Nevertheless, differences among years were mostly environmental. Males received lower scores for almost all morphological and gaits traits except croup, with a difference of about -1.7 points for final score relative to females. Sex differences were small for functional traits, with general advantage of males in WEMT and CD, and a disadvantage in WEDT. Considerable differences were detected among studs, especially in their environmental effects but also in mean estimated breeding value (EBV), for morphology, gaits and functionality. The environmental effect of competition level in $\mathrm{CD}$ resulted in a progressively lower scoring as the competition became more difficult, while for WEMT the pattern was opposite and differences were minor for WEDT. Inbreeding depression was observed for all morphological and gait traits, but the magnitude of its impact was very small for all traits analyzed, never exceeding $-0.1 \%$ of the mean per $1 \%$ inbreeding. Still, for functional traits the effect of inbreeding was negligible. The EBV for morphology, gaits, WEMT and WEDT show considerable variability, indicating that selection can be effective. For $\mathrm{CD}$, however, the distribution of EBV was narrower. The genetic trend was positive but moderate for all traits, and it was slightly higher for head and neck, overall impression, gaits and final score. As a percentage of the mean, these traits and working equitation trials showed the highest responses, which in the best cases did not exceed $0.2 \%$ of the mean per year. Genetic selection differentials and the corresponding selection intensities were very modest for all traits analyzed, with a slightly higher intensity in sires when compared to dams.
\end{abstract}

(c) 2014 Elsevier B.V. All rights reserved.

\footnotetext{
* Corresponding author. Tel.: +351 213652800; fax: +351 213652889.

E-mail address: Itgama@fmv.ulisboa.pt (L.T. Gama).
} 


\section{Introduction}

The Lusitano is included in what is considered the Baroque type of horse, known for its elegance and graciousness (Bowling and Ruvinsky, 2000; Loch, 1986). Historically, Lusitano horses have been selected mostly based on aesthetical criteria, but their continuous use in different field work activities and in horse-mounted bullfighting has maintained their functional characteristics and versatility (Gonzaga, 2004).

Since the establishment of the Lusitano Studbook in 1967, the selection program has emphasized mainly conformation and gaits traits, graded by visual assessment. However, some studs have applied more specialized breeding objectives, following the traditional selection of Lusitano horses for their ability in classical riding and equestrian art, but also their aptitude for bullfighting and herd management. In more recent years, the goal of improving performances in dressage, working equitation and carriage driving competitions has gained importance in the selection of Lusitano. Nevertheless, no systematic breeding value estimation has been applied nor used in selection decisions so far, and it is not clear how much weight breeders are actually giving to different traits when selection is practiced.

Horse selection programs in Europe generally include both performance and non-performance traits (Koenen et al., 2004), and the implementation of organized selection programs has resulted in positive responses in several horse breeds, as reviewed by Arnason and Van Vleck (2000). A positive genetic trend has been achieved in different equestrian disciplines, including dressage, show jumping, eventing and endurance (Ricard and Touvais, 2007; Thoren Hellsten et al., 2009; Viklund et al., 2011), but also in conformation aspects (Albertsdottir et al., 2011; Fioretti et al., 2005; Miglior et al., 1998). For racing performance, however, the results have been less consistent, because even though a positive genetic trend for speed has been reported for several breeds (Gaffney and Cunningham, 1988; Klemetsdal, 1992; Mota et al., 2005; Oki and Sasaki, 1996; Olsen et al., 2011; Willham and Wilson, 1991), no reduction in winning times has been observed for the major horse races over the last 50 years (Gardner, 2006). Several fixed factors are known to affect horse traits and performances, including the effects of sex, stud, year, event, etc., and they are often included in the statistical models used in genetic evaluations (Bruns et al., 2004). One of the major fixed factors considered when practicing selection is the inbreeding coefficient, to account for the detrimental effect of inbreeding on performance known as inbreeding depression (Falconer and MacKay, 1996). Still, it has been argued that the severity of inbreeding depression seems to be lower in horses when compared with other species (Ballou, 1994).

Over the years, in addition to the several generations of pedigree data, a comprehensive amount of information has been gathered regarding conformation, gaits and, to a lesser extent, functional traits in Lusitano horses. These data have been recently analyzed by our group with the goal of characterizing the demography of the population (Vicente et al., 2012) and estimating genetic parameters for those traits (Vicente et al., 2014), as these represent crucial initial steps in the consolidation of the breeding program and provide the foundations for more objective selection decisions. Furthermore, in the Lusitano horse no systematic analysis of fixed effects, including inbreeding depression, has been carried out, even though the breed currently has a mean inbreeding of about $11 \%$ and the effective population size is only about 28 (Vicente et al. 2012), making it an interesting model to assess the magnitude of inbreeding depression for conformation and performance, as well as to determine the importance of other fixed factors.

In this work, we used pedigree, morphology, gaits and functional records for the Lusitano horse breed, analyzed by mixed model procedures, to (a) investigate the importance of different fixed effects, including inbreeding; (b) assess the distribution of estimated breeding values for different traits; (c) study the realized phenotypic and genetic trends over a period of 40 years; and (d) appraise retrospectively the success of the breeding program.

\section{Materials and methods}

\subsection{Animals and data}

In this study we analyzed conformation and gaits records collected in Lusitano horses over a period of more than 40 years, and functional records collected since 1998 , to obtain detailed baseline information about the factors affecting those traits, and to carry-out a critical assessment of the selection applied in this breed. The data set analyzed and the procedures followed in this work have been described in detail by Vicente et al. (2014). Briefly, pedigree and performance records for Lusitano registered horses were obtained from Fundação Alter Real (Portuguese National Stud) and Portuguese Association of Lusitano Horse Breeders (Associação Portuguesa de Criadores do Cavalo Puro-Sangue Lusitano, APSL), as well as from other sources maintaining performance results for Lusitano horses, such as the International Equestrian Federation and National Equestrian Federations.

Records were edited to exclude ages below 2 years-old and a few cases of single records in a contemporary group, as described by Vicente et al. (2014). Contemporary groups were well connected, given the depth of the pedigrees used such that, overall, the mean relationship existing among animals from different studs was 0.15 (Vicente et al., 2012). After validation of pedigree records, information on 53,417 horses registered in the Studbook and born between 1824 and 2009 was used. At the time of registration in the breeders section, animals are scored for different morphological traits and gaits (GA), and height at withers (HW) is measured. The morphological traits considered in this grading are head and neck (HN), shoulder and withers (SW), chest and thorax (CT), back and loin (BL), croup (CR), legs (LE) and overall impression (OI). All the morphological traits and GA are scored in a scale $1-10$, and they are then combined into a final score (FS) obtained as $[(\mathrm{HN}+\mathrm{SW}+\mathrm{CT}+\mathrm{CR})+1.5$ $(\mathrm{BL}+\mathrm{LE}+\mathrm{OI}+\mathrm{GA})]$. Gaits and morphological scores were obtained in up to 18,076 animals, in the period of 1967 2009 (Table 1). 
Table 1

Number of records and number of fixed effects considered in the analyses of partial morphological scores and gaits, final score (FS), height at withers (HW), working equitation dressage trial (WEDT), working equitation maneability trial (WEMT) and classical dressage $(\mathrm{CD})$ in Lusitano horses.

\begin{tabular}{|c|c|c|c|}
\hline Group of traits & Trait & Item & No. levels \\
\hline \multirow[t]{9}{*}{ Morphology and gaits } & All partial morphological & Studs & 863 \\
\hline & scores and gaits & Years & 43 \\
\hline & & Horses & 17,139 \\
\hline & FS & Studs & 904 \\
\hline & & Years & 43 \\
\hline & & Horses & 18,076 \\
\hline & HW & Studs & 847 \\
\hline & & Years & 43 \\
\hline & & Horses & 16,955 \\
\hline \multirow[t]{9}{*}{ Functional traits } & WEDT & Events & 109 \\
\hline & & Levels of competition & 5 \\
\hline & & Records/horses & $1454 / 186$ \\
\hline & WEMT & Events & 110 \\
\hline & & Levels of competition & 5 \\
\hline & & Records/horses & $1524 / 211$ \\
\hline & $\mathrm{CD}$ & Events & 1379 \\
\hline & & Levels of competition & 11 \\
\hline & & Records/horses & $12,131 / 759$ \\
\hline
\end{tabular}

Table 2

Number of records, means and standard deviations (SD) for fixed effects included in the models used in analyses of partial morphological scores and gaits, final score (FS), height at withers (HW), working equitation dressage trial (WEDT), working equitation maneability trial (WEMT) and classical dressage (CD) in Lusitano horses.

\begin{tabular}{|c|c|c|c|c|c|c|c|}
\hline \multirow[t]{2}{*}{ Group of traits } & \multirow[t]{2}{*}{ Trait } & \multicolumn{2}{|l|}{ Sex } & \multicolumn{2}{|c|}{ Age at classification (years) } & \multicolumn{2}{|c|}{ Inbreeding (\%) } \\
\hline & & No. records males & No. records females & Mean & SD & Mean & SD \\
\hline \multirow[t]{3}{*}{ Morphology and gaits } & $\begin{array}{l}\text { All partial morphological } \\
\text { scores and gaits }\end{array}$ & 4794 & 12,345 & 6.38 & 3.01 & 10.03 & 8.49 \\
\hline & FS & 5283 & 12,793 & 6.39 & 3.00 & 10.07 & 8.46 \\
\hline & HW & 4619 & 12,336 & 6.37 & 3.02 & 10.01 & 8.48 \\
\hline \multirow[t]{3}{*}{ Functional traits } & WEDT & 1384 & 70 & 8.63 & 2.66 & 11.52 & 9.24 \\
\hline & WEMT & 1449 & 75 & 8.66 & 2.70 & 11.36 & 9.15 \\
\hline & $\mathrm{CD}$ & 11,204 & 927 & 9.19 & 3.35 & 8.13 & 6.26 \\
\hline
\end{tabular}

In addition to morphology and gaits, we used 12,131 performance records from classical dressage (CD) events where Lusitano horses participated, and information from working equitation events, including 1454 records obtained in dressage trials (WEDT) and 1524 in maneability trials (WEMT) of working equitation (Table 2). Functionality traits correspond to the mean scores attributed by a group of three to five judges in a scale $0-100$. For both $C D$ and working equitation, competitions are classified into different levels of difficulty, reflecting the hardship of the test, age of the horse and seniority of the rider, and in our study there were 11 levels recognized for dressage and 5 levels for working equitation. Further details on the classification of morphological traits, CD, WEDT and WEMT have been reported elsewhere (Vicente et al., 2014).

Individual coefficients of inbreeding were computed using all the pedigree information available, as described by Vicente et al. (2012), such that for the full data set analyzed, the mean inbreeding coefficient was $9.92 \pm 8.34 \%$, based on a mean of about 10 equivalent generations.

\subsection{Statistical analysis}

Preliminary analyses of variance were carried-out with the GLM procedure of SAS (SAS Institute, 2004) to assess the relative importance of the fixed effects included in the mixed linear model used in further analyses.

The major goal of our analyses was to obtain estimates of fixed effects and breeding values for morphological and functional traits in Lusitano horses, by mixed model procedures using a BLUP - Animal Model. In a first stage, mixed models were used to obtain estimates of variance components by Restricted Maximum Likelihood, in univariate analyses using the MTDFREML package (Boldman et al., 1995). Morphology and gait traits were scored only once in the lifetime of the individual, while for functional traits the same animal could be classified several times, depending on the number of competitions that it entered. Therefore, the statistical model used in the analysis of morphology and gaits traits was a single trait Animal Model with single records, while for functional traits the 
univariate model used allowed the existence of repeated records by the same horse.

In matrix notation, the mixed model used in the analyses of morphology and gaits was

$y=X b+Z_{a} a+e$

where $y$ is the vector of records for morphology and gaits, $b$ is the vector of fixed effects to be estimated and $X$ the corresponding incidence matrix relating records to fixed effects, $a$ is the vector of breeding values to be estimated and $Z_{a}$ the corresponding incidence matrix, and $e$ is the vector of residuals. In this case, the fixed effects considered in vector $b$ were stud, year of classification and sex, plus the linear effect of inbreeding and the linear and quadratic effect of age at scoring as covariables. In preliminary analyses, the quadratic effect of inbreeding was also included in the model, but it was found to be not significant $(P>0.05)$, so it was removed from final analyses.

In the univariate analyses of dressage and working equitation, in matrix notation the mixed model used was

$y=X b+Z_{a} a+Z_{c} c+e$

where $y$ is the vector of records for CD, WEDT and WEMT, $c$ is the vector of permanent environmental effects of the horse to be estimated and $Z_{c}$ is the corresponding incidence matrix, and the other abbreviations are as defined previously. In the case of dressage and working equitation results, the fixed effects considered in the Animal Model were sex, event (defined as the combination of place and date of the competition) and level of difficulty, plus the linear effect of inbreeding and the linear and quadratic effect of age at competition as covariables.

The MTDFREML package (Boldman et al., 1995) was used to obtain estimates of variance components by Restricted Maximum Likelihood, iterating until a convergence criterion of $10^{-12}$ was obtained. The analyses were carried-out considering in the relationship matrix the known ancestors of animals with records, such that there were 21,480 animals in the pedigree file used in the analysis of morphology and gaits traits, 22,046 in CD and 3480 in WEDT and WEMT. The estimated variance components, which have been reported elsewhere (Vicente et al., 2014), were then used to obtain estimates of fixed and random effects for each trait in univariate analyses.

Inbreeding depression was estimated for the analyzed traits in MTDFREML, from their regression coefficients on the coefficient of inbreeding, which was included as a linear covariate in the model. In order to assess the relative impact of inbreeding on the different traits, a standardized regression coefficient was obtained by dividing the linear regression coefficients by their phenotypic standard deviation and also expressed as a percentage of the mean.

\subsection{Selection in retrospect}

Genetic trends over time were assessed by regressing the estimated breeding values (EBV) for each trait on year of birth. To allow comparisons of the magnitude of selection response achieved in different traits, the regression coefficient estimated as above for a given trait was divided by its corresponding genetic standard deviation, to obtain an estimate of the standardized genetic trend, and also expressed as a percentage of the trait mean.

To assess the relative emphasis placed on selected traits throughout the period studied, selection differentials were calculated in retrospect. For these analyses, the EBV for different traits were averaged by year of birth for males and females in the whole population, and for the selected sample which later produced registered offspring. The difference between the mean EBV for selected individuals and for the whole group born in the same year was considered the genetic selection differential. These selection differentials were then pooled by sex across years for the whole period studied and for the last 6 years of selection, i.e., animals born in the period 2000-2005. Selection intensity was then calculated by dividing the pooled annual genetic selection differential for each trait by the corresponding genetic standard deviation, as reported by Vicente et al. (2014).

\section{Results}

\subsection{Descriptive statistics and phenotypic trends}

The number of records and levels of fixed effects considered in the analyses of morphology, gaits and functional traits are summarized in Table 1. The records included in the analysis of morphology and gaits traits were obtained in about 18,000 horses, originating from about 900 studs in a period of 43 years. The number of horses with information on performance traits was much smaller (about 760 for CD and nearly 200 for WEDT and WEMT), with a mean of 16.0, 7.8 and 7.2 records/horse for CD, WEDT and WEMT, respectively.

For morphology and gaits traits, there were about 2.5 times more records for females than males (Table 2), while for functional traits the number of records produced by males, when compared with females, was about 12 times more in CD and 19 times more in WEDT and WEMT. The mean age at classification of morphological and gaits traits was about 6.4 years, with a coefficient of variation (CV) of nearly $50 \%$, while for $\mathrm{CD}$ and working equitation the means were about 9.2 and 8.7 years, respectively, with a CV of nearly $30 \%$. The mean coefficient of inbreeding was about $10 \%$ for the animals included in the analysis of morphology and gaits, $11.5 \%$ for working equitation and $8 \%$ for CD, with a CV of about $80 \%$.

Over the period of 40 years analyzed, the phenotypic trends for morphology (Fig. 1a) indicate that HW increased by about $0.053 \mathrm{~cm} /$ year, while FS declined steadily, on average 0.11 points/year. For functional traits, no phenotypic change could be detected in the period of 20 years studied (Fig. 1b), with year means that were very stable for $\mathrm{CD}$, but showed considerable variation from year to year for WEDT and WEMT.

\subsection{Fixed effects}

Preliminary analyses of variance indicated that the fixed effects considered in the models used for analyzing morphological and functional traits accounted for about $14-35 \%$ of the phenotypic variability (results not shown). 
a

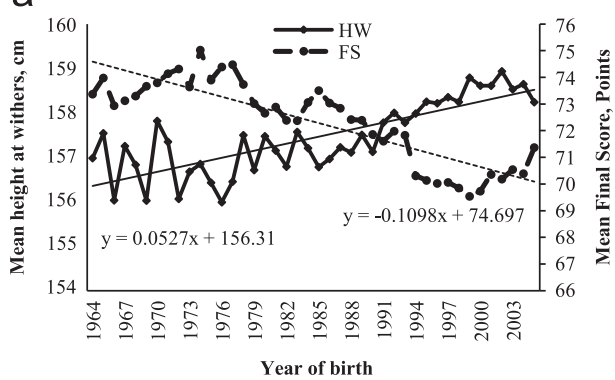

b

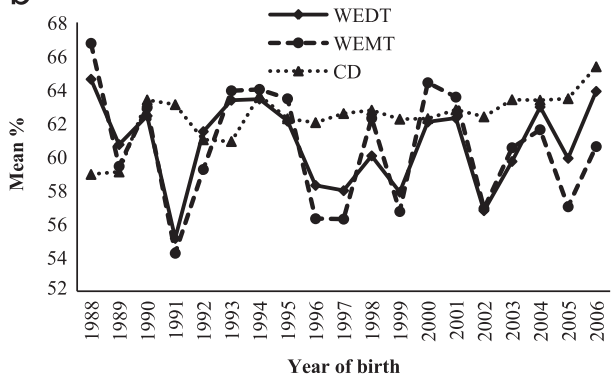

Fig. 1. Means by year of birth for: (a) morphological traits - final score (FS) and height at withers (HW), with corresponding time trend, and (b) functional traits - working equitation dressage trial (WEDT), working equitation maneability trial (WEMT) and classical dressage (CD).
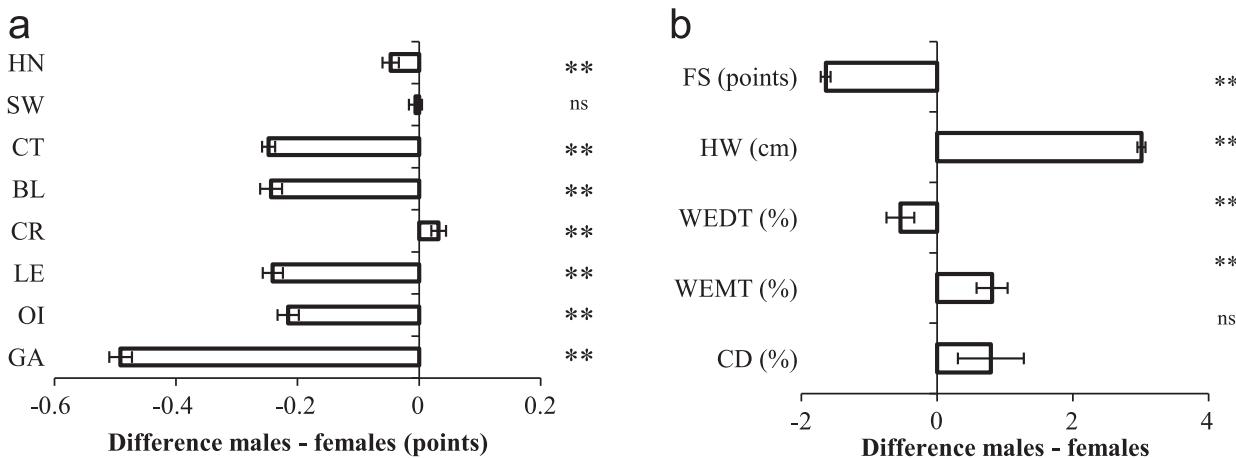

Fig. 2. Differences between sex fixed effects for: a) gaits and morphology partial scores (points); b) morphology final score (FS, points), height at withers $(\mathrm{HW}, \mathrm{cm})$ and functional traits - classical dressage (CD), working equitation dressage trial (WEDT) and maneability trial (WEMT) (\%). Significance of the differences represented as ns: non-significant; ${ }^{* *} P<0.01$.

Genetic parameters were estimated in a first-stage analysis with MTDFREML, and in the second stage these estimates were used to obtain solutions and contrasts for fixed effects and EBV in the mixed model, using the same software package. The difference between sex fixed effects for the traits analyzed (Fig. 2) indicates that, on average, males receive significantly lower scores for all morphological traits $(P<0.01)$, except SW $(P>0.05)$, while for $\mathrm{CR}$ the higher score was attributed to males $(P<0.01)$. When grading GA, males received a score lower by about 0.5 points relative to females $(P<0.01)$ while for FS the difference was almost -1.7 points $(P<0.01)$. Sex differences for functional traits were small, with an advantage in males of about 0.8 percentage points for WEMT $(P<0.01)$ and CD $(P>0.05)$, and a disadvantage of -0.54 percentage points for WEDT $(P<0.01)$.

The distribution of stud fixed effects for FS followed an approximately normal distribution, with very large environmental differences among studs, while for HW the distribution was also normal but narrower (results not shown).

The level of competition was included as a fixed effect in the analysis of functional traits, and the corresponding solutions are shown in Fig. 3. The degree of difficulty of the competition had an important effect on the score obtained in CD (Fig. 3a), such that, in both national-level (from preliminary to complementary) and international-level (from FEI4years to Big Tour) competitions, the environmental effect of competition level resulted in an increasingly lower scoring as the competition became more difficult and complex. For WEDT (Fig. 3b), differences among competition levels were minor, except for some penalizing in the Juvenile class, which corresponds to competitors up to 16 years of age. For WEMT (Fig. 3b), the environmental effect of competition level resulted in an increase in average scoring as the level of competition increased, from Juvenile to Master.

Inbreeding had a negative impact on all partial morphological scores analyzed (Table 3 ), with a significant effect $(P<0.05)$ on all traits except HN. The consequences of inbreeding were also detrimental $(P<0.01)$ for the global assessment of morphology (FS), as well as for HW and GA. For functional traits, however, the impact of inbreeding was small $(P>0.05)$ even though negative. To allow comparisons of the relative impact of inbreeding on different traits, a standardized partial regression coefficient was obtained, using phenotypic standard deviation as the weighing factor (Table 3). In these analyses, the traits showing a stronger inbreeding depression were HW, LE, GA and CR, and the minimum impact of inbreeding in standard deviation units was detected in HN and SW, while for functional traits the impact was intermediate. When inbreeding depression was expressed in percentage of the trait means (Table 3), the traits showing a larger impact were CR, LE and GA, followed by functional traits. Still, the overall effect of inbreeding was negligible for all the traits analyzed, never exceeding $-0.1 \%$ of the trait mean by $1 \%$ inbreeding. 
a

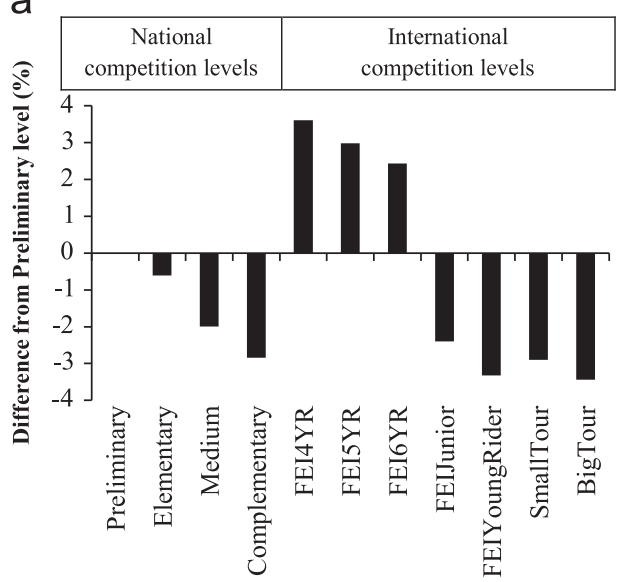

Level of Competition b

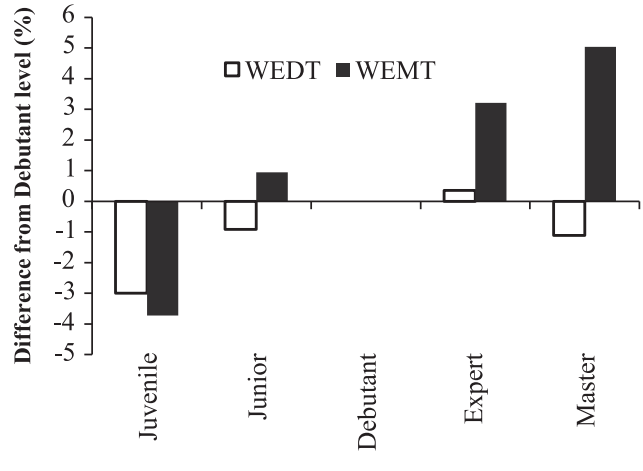

Level of Competition

Fig. 3. Graphical representation of the fixed effect of level of competition for: (a) classical dressage, expressed as deviation from Preliminary level of competition and (b) working equitation dressage trial (WEDT) and maneability trial (WEMT), expressed as deviation from Debutant level of competition.

Table 3

Inbreeding depression estimated by the regression coefficient $\left(b_{\text {trait.fi }} \pm \mathrm{SE}\right)$ of each morphological and functional trait on the individual inbreeding coefficient in percentage units, and standardized regression coefficient expressed in phenotypic standard deviation units $\left(\beta_{\text {trait.fi }}\right)$ and in percentage relative to the trait mean.

\begin{tabular}{|c|c|c|c|c|}
\hline Group of traits & Trait $^{\mathrm{a}}$ & $b_{\text {trait.fi }} \pm \mathrm{SE}^{\mathrm{b}}$ & $\beta_{\text {trait.fi }}$ & Percentage of mean \\
\hline \multirow[t]{10}{*}{ Morphology and gaits } & $\mathrm{HN}$ & $-0.0010 \pm 0.0010^{\mathrm{ns}}$ & -0.001 & -0.01 \\
\hline & SW & $-0.0018 \pm 0.0008^{*}$ & -0.003 & -0.02 \\
\hline & $\mathrm{CT}$ & $-0.0029 \pm 0.0008^{* * *}$ & -0.005 & -0.04 \\
\hline & $\mathrm{BL}$ & $-0.0038 \pm 0.0013^{* * *}$ & -0.006 & -0.06 \\
\hline & $\mathrm{CR}$ & $-0.0061 \pm 0.0008^{* * *}$ & -0.009 & -0.08 \\
\hline & LE & $-0.0050 \pm 0.0011^{* *}$ & -0.008 & -0.07 \\
\hline & OI & $-0.0038 \pm 0.0012^{* * *}$ & -0.006 & -0.05 \\
\hline & GA & $-0.0060 \pm 0.0013^{* * *}$ & -0.009 & -0.08 \\
\hline & FS & $-0.0314 \pm 0.0052^{* *}$ & -0.007 & -0.04 \\
\hline & HW & $-0.0346 \pm 0.0042^{* * *}$ & -0.009 & -0.02 \\
\hline \multirow[t]{3}{*}{ Functional traits } & WEDT & $-0.0412 \pm 0.0572^{\mathrm{ns}}$ & -0.006 & -0.07 \\
\hline & WEMT & $-0.0386 \pm 0.0627^{\mathrm{ns}}$ & -0.004 & -0.06 \\
\hline & $\mathrm{CD}$ & $-0.0360 \pm 0.0201^{\mathrm{ns}}$ & -0.008 & -0.06 \\
\hline
\end{tabular}

${ }^{a}$ Head and neck (HN), shoulder and withers (SW), chest and thorax (CT), back and loin (BL), croup (CR), legs (LE), overall impression (OI), gaits (GA), final score (FS), height at withers (HW), working equitation dressage trial (WEDT), working equitation maneability trial (WEMT) and classical dressage (CD). Morphological traits expressed in a scale of $0-10$ points, except for FS (0-100 points scale) and HW (cm). Functional traits expressed in percentage points.

${ }^{\mathrm{b}}$ Significance of regression coefficients: ${ }^{\mathrm{ns}}$ non-significant; ${ }^{*} P<0.05$; ${ }^{* *} P<0.01$.

Age at classification had a significant quadratic effect on all traits analyzed, and its effect on FS and HW is illustrated in Fig. 4. The FS declined slightly as age increased, while HW increased up to about 9 years of age and stabilized afterwards. For functional traits, the effect of age at competition was essentially linear with a significant $(P<0.05)$ increase in scoring as age increased, which was very moderate in $\mathrm{CD}$, but more pronounced in working equitation trials (results not shown).

\subsection{Genetic trends}

The effectiveness of selection practiced was assessed by investigating genetic trends for the traits analyzed (Table 4), obtained by regressing EBV on year of birth. For all the morphology, gaits and functional traits analyzed, the regression of EBV on year of birth was positive and significant, indicating that selection has been effective, even though the magnitude of response has been quite modest in all cases. When selection response for each trait is expressed in genetic standard deviation units, the traits showing a better response were HN, OI, FS and GA, while the morphological traits showing a higher response were $\mathrm{HN}$, OI and GA, followed by working equitation trials with a response of similar magnitude.

\subsection{Variability of estimated breeding values}

The distribution of EBV in the whole population and in animals selected for breeding is shown in Fig. 5 for the major morphological traits (FS and HW), GA, and for functional traits. The observed distribution was approximately normal 
a

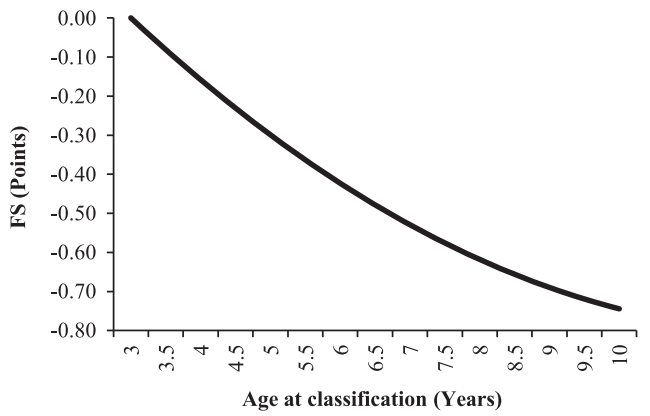

b

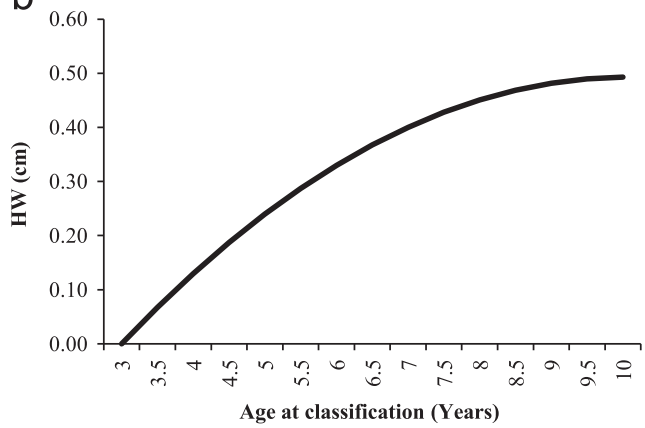

Fig. 4. Graphical representation of the fixed effect of age at classification on: (a) final score (FS) and (b) height at withers (HW).

Table 4

Genetic trends estimated by the regression coefficient of estimated breeding values for each morphological and functional trait on year of birth ( $b_{\text {trait.year }} \pm \mathrm{SE}$ ) for animals born after 1960 , standardized regression coefficient in genetic standard deviation units $\left(\beta_{\text {trait.year }}\right)$ and genetic trend expressed in percentage of the trait mean.

\begin{tabular}{lllll}
\hline Trait $^{\mathrm{a}}$ & Unit & $b_{\text {trait.year }} \pm \mathrm{SE}^{\mathrm{b}}$ & $\beta_{\text {trait.year }}$ & $\begin{array}{l}\text { Percentage } \\
\text { of mean }\end{array}$ \\
\hline HN & Points & $0.010 \pm 0.0001^{* *}$ & 0.031 & 0.137 \\
SW & & $0.002 \pm 0.0001^{* *}$ & 0.010 & 0.030 \\
CT & & $0.002 \pm 0.0001^{* *}$ & 0.012 & 0.032 \\
BL & & $0.007 \pm 0.0001^{* *}$ & 0.017 & 0.097 \\
CR & & $0.002 \pm 0.0001^{* *}$ & 0.009 & 0.030 \\
LE & & $0.002 \pm 0.0001^{* *}$ & 0.007 & 0.024 \\
OI & & $0.011 \pm 0.0001^{* *}$ & 0.029 & 0.148 \\
GA & & $0.010 \pm 0.0001^{* *}$ & 0.023 & 0.133 \\
FS & & $0.050 \pm 0.0005^{* *}$ & 0.028 & 0.070 \\
HW & $\mathrm{cm}$ & $0.006 \pm 0.0008^{* * *}$ & 0.002 & 0.004 \\
WEDT & $\%$ & $0.072 \pm 0.0010^{* * *}$ & 0.017 & 0.118 \\
WEMT & & $0.064 \pm 0.0008^{* * *}$ & 0.016 & 0.105 \\
CD & & $0.029 \pm 0.0005^{* *}$ & 0.011 & 0.046 \\
\hline
\end{tabular}

${ }^{a}$ Head and neck (HN), shoulder and withers (SW), chest and thorax $(\mathrm{CT})$, back and loin (BL), croup (CR), legs (LE), overall impression (OI), gaits (GA), final score (FS), height at withers (HW), working equitation dressage trial (WEDT), working equitation maneability trial (WEMT) and classical dressage (CD).

b Significance of regression coefficients: ${ }^{* *} P<0.01$

for all traits, with minor differences between the selected individuals and the whole population. When the whole population was considered, large differences in EBV were detected among individuals for FS, exceeding 6 points between extreme animals (scale $0-100$ points), which supports the feasibility of selecting with success for FS based on EBV, and a similar pattern was observed for HW. Differences in EBV for GA were smaller but still important, indicating that selection could be effective in improving GA in Lusitano horses. For functionality, the variability of EBV was important for all traits, but their distribution was wider for working equitation trials than for $\mathrm{CD}$.

The standard deviation (SD) of EBV found in this work can be compared with the genetic SD estimated from the same data (Vicente et al., 2014), and both are summarized in Table 5. It is expected that the SD of EBV should be smaller than the true genetic SD by a factor of $r_{\mathrm{AP}}$, where $r_{\mathrm{AP}}$ corresponds to the mean accuracy of selection (Van Vleck, 1993), which in mixed-model analyses largely depends on heritability and on the amount of family information considered. In our analyses, the ratio between the SD of EBV relative to the estimated genetic $S D$ ranged from about 0.58 to 0.64 for global morphology (FS and HW), while for functional traits the ratio was between 0.41 and 0.51 . These results indicate that selection accuracy was somewhat lower for functional traits, as would be expected given their much lower number of records, in spite of the higher heritability of WEDT and CD when compared with FS (Vicente et al., 2014).

The EBV were averaged by stud, and the corresponding means for FS, HW, WEDT, WEMT and CD are in Fig. 6. Important genetic differences between studs were observed for all these traits, indicating that selection among different studs could play an important role in the success of the breeding program.

\subsection{Selection differentials}

In the period of 35 years considered in our study, it is apparent that the selection differential has consistently been much smaller in females than in males (Fig. 7), and no trait could be easily identified as being under selection in mares, except for some emphasis on WEDT and WEMT in the last few years. In males, no genetic selection has being applied on HW over the period analyzed, and in the last 10 years more attention is being given to working equitation trials. The genetic selection differentials for each trait, pooled over the years analyzed, and the corresponding selection intensity are in Table 5. Selection differentials were much larger in sires than in dams, by a factor of about 2-10. Among the partial morphological scores, the one receiving more weight in males was $\mathrm{HN}$, and in females OI and GA. When selection differentials were computed for the whole period analyzed and for the period 2000-2005 alone, it was noticeable that, in the last period, the selection differential for HW increased by almost 5-fold in stallions, while in mares it was FS which increased in the last period. Selection differentials for functional traits have increased in the last few years, while for SW, CT, CR and LE the selection differential has been nearly non-existent throughout the period analyzed. Overall, the mean selection intensity (Table 5) has been the highest for HN, BL, OI, GA and FS, followed by functional traits, which have received more attention in the last few years. 


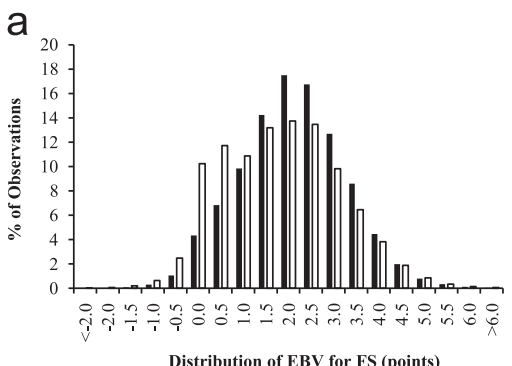

Distribution of EBV for FS (points)

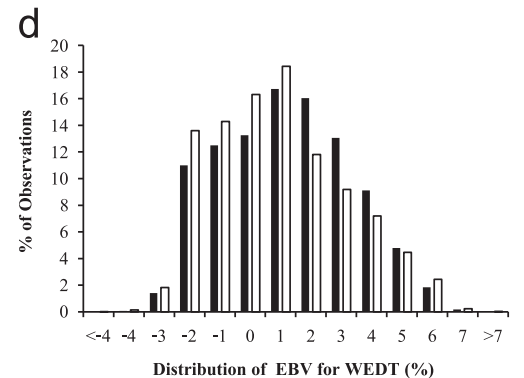

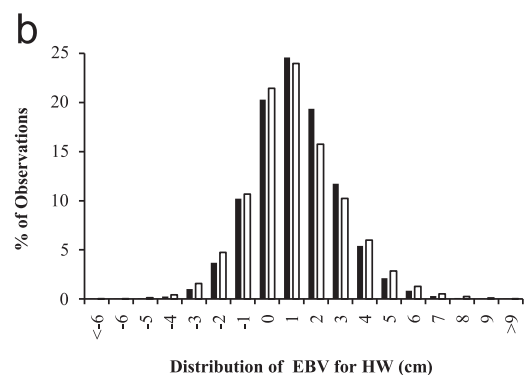

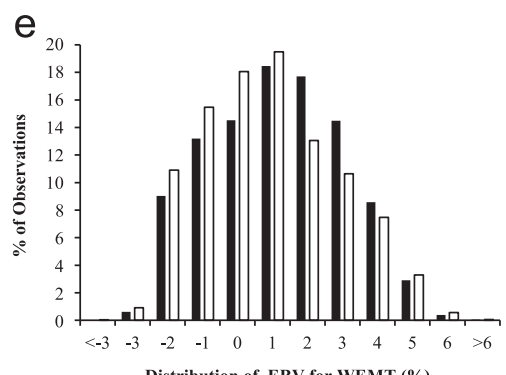

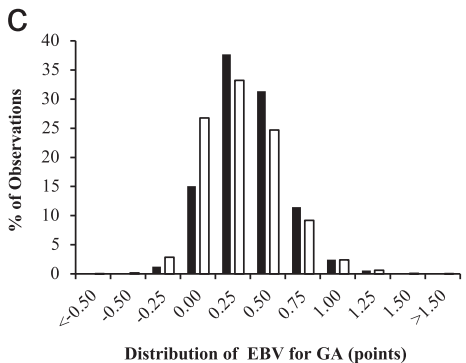

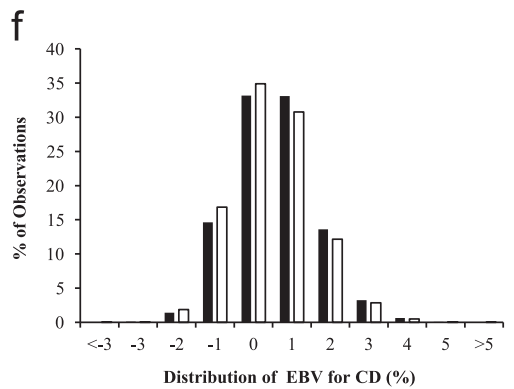

Fig. 5. Distribution of estimated breeding values (EBV) for: (a) final score (FS); (b) height at withers (HW); (c) gaits (GA); (d) working equitation dressage trial (WEDT); (e) working equitation maneability trial (WEMT); and (f) classical dressage (CD), in the full data set ( $\mathbf{m})$ and in selected animals with registered offspring $(\square)$.

Table 5

Standard deviation of estimated breeding values (EBV), estimated genetic standard deviation, and annual genetic selection differentials assessed in retrospect for sires and dams and corresponding selection intensity averaged over sexes, for morphological and functional traits pooled across years of birth in Lusitano horses, considering the whole period analyzed (1967-2005) or animals born between 2000 and 2005.

\begin{tabular}{|c|c|c|c|c|c|c|c|c|}
\hline \multirow[t]{3}{*}{ Trait $^{\mathrm{a}}$} & \multirow[t]{3}{*}{ EBV standard deviation } & \multirow[t]{3}{*}{ Genetic standard deviation $^{\mathrm{b}}$} & \multicolumn{4}{|c|}{ Mean genetic selection differential } & \multicolumn{2}{|c|}{ Mean selection intensity } \\
\hline & & & \multicolumn{2}{|c|}{ 1967-2005 } & \multicolumn{2}{|c|}{ 2000-2005 } & \multirow[t]{2}{*}{ 1967-2005 } & \multirow[t]{2}{*}{ 2000-2005 } \\
\hline & & & Sires & Dams & Sires & Dams & & \\
\hline $\mathrm{HN}$ & 0.245 & 0.319 & 0.0918 & 0.0204 & 0.1012 & 0.0532 & 0.176 & 0.242 \\
\hline SW & 0.103 & 0.217 & 0.0185 & 0.0069 & 0.0151 & 0.0219 & 0.057 & 0.085 \\
\hline $\mathrm{CT}$ & 0.102 & 0.210 & 0.0169 & 0.0092 & 0.0108 & 0.0219 & 0.062 & 0.078 \\
\hline $\mathrm{BL}$ & 0.200 & 0.265 & 0.0618 & 0.0202 & 0.0774 & 0.0481 & 0.152 & 0.236 \\
\hline CR & 0.131 & 0.259 & 0.0125 & 0.0094 & 0.0074 & 0.0150 & 0.042 & 0.043 \\
\hline LE & 0.086 & 0.158 & 0.0095 & 0.0068 & 0.0153 & 0.0176 & 0.052 & 0.104 \\
\hline OI & 0.238 & 0.241 & 0.0903 & 0.0258 & 0.1068 & 0.0693 & 0.239 & 0.364 \\
\hline GA & 0.250 & 0.285 & 0.0749 & 0.0256 & 0.0824 & 0.0707 & 0.176 & 0.268 \\
\hline FS & 1.154 & 1.800 & 0.4144 & 0.1396 & 0.4441 & 0.3616 & 0.153 & 0.224 \\
\hline HW & 1.725 & 2.980 & 0.0740 & 0.0495 & 0.3433 & 0.0841 & 0.019 & 0.072 \\
\hline WEDT & 2.131 & 4.186 & 0.6790 & 0.1130 & 0.8669 & 0.3646 & 0.096 & 0.147 \\
\hline WEMT & 1.059 & 4.038 & 0.6227 & 0.1024 & 0.7996 & 0.3464 & 0.091 & 0.142 \\
\hline CD & 1.893 & 2.614 & 0.3179 & 0.0454 & 0.4190 & 0.1397 & 0.069 & 0.107 \\
\hline
\end{tabular}

${ }^{a}$ Head and neck (HN), shoulder and withers (SW), chest and thorax (CT), back and loin (BL), croup (CR), legs (LE), overall impression (OI), gaits (GA), final score (FS), height at withers (HW), working equitation dressage trial (WEDT), working equitation maneability trial (WEMT) and classical dressage (CD). Morphological partial scores and gaits measured in a scale of 0-10 points; FS obtained by summing partial scores, weighing BL, LE, OI and GA by 1.5 , and other partial scores by 1.0; HW in cm; WEDT, WEMT and CD expressed in \%.

${ }^{\mathrm{b}}$ From Vicente et al. (2014).

One possible reason for the lower than expected selection differentials is the sub-optimal use of outstanding animals, and this possibility was investigated by obtaining the relationship between the FS attributed to a sire and its number of registered offspring. The estimated correlation was moderate $(r=0.277)$ but significant $(P<0.01)$, indicating that there is a weak positive association between the morphology score (FS) obtained by a sire and the number of offspring that it produced.

\section{Discussion}

The Lusitano horse has a long tradition as a saddle breed, and its Studbook was established in 1967 (Vicente et al., 2012). The official selection program implemented by the breeders' association is mainly based on the adherence of an animal to the breed standard, expressed by its scoring in morphology and gaits items. In addition, studs have over the years selected their animals based on 

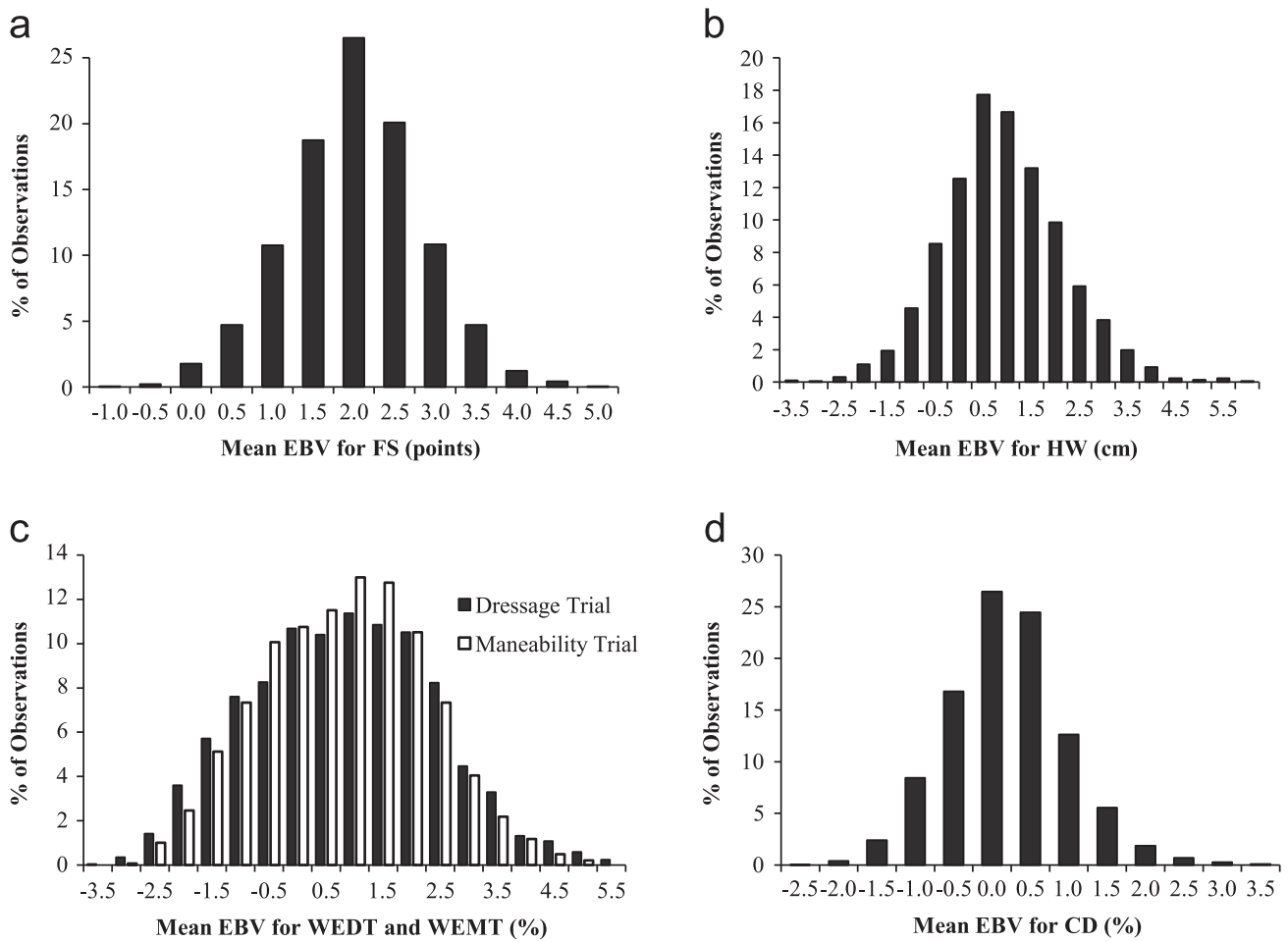

Fig. 6. Distribution of stud means for estimated breeding values (EBV) for: (a) final score (FS); (b) height at withers (HW); (c) working equitation dressage (WEDT) and maneability (WEMT) trials; and (d) classical dressage (CD).
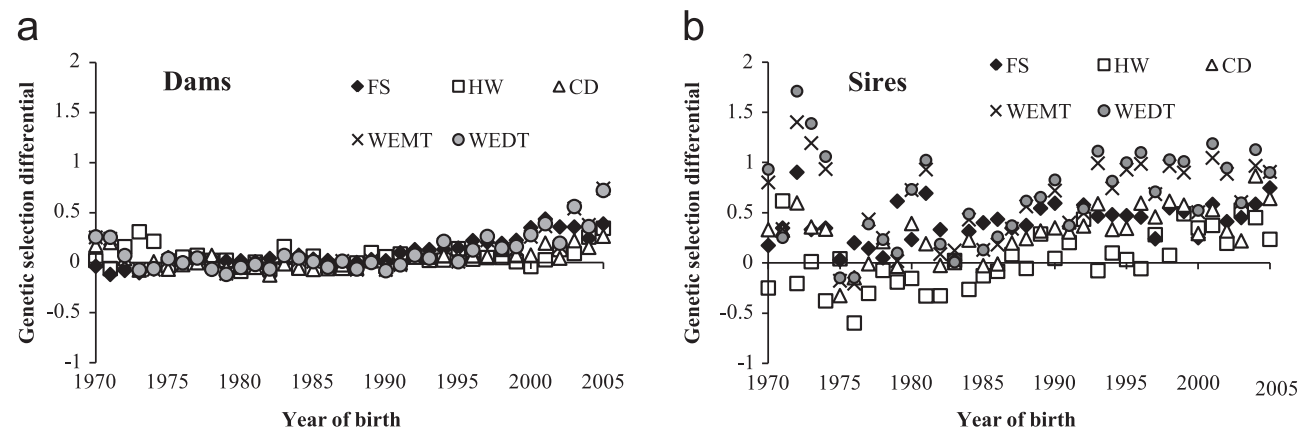

Fig. 7. Retrospective genetic selection differentials in Lusitano: (a) dams and (b) sires, for morphological (final score, FS; height at withers, HW) and functional (classical dressage, CD; working equitation dressage trial, WEDT; and working equitation maneability trial, WEMT) traits, by year of birth.

beauty, conformation and ability for equestrian art and bullfighting, and in the last few years, selection for sports activities such as dressage has been part of the breeding goal for some Lusitano breeders. Still, no systematic data collection or genetic evaluation for these traits has been carried out (Vicente et al., 2014), but it is acknowledged that providing breeders with more objective tools when selecting their breeding stock would enhance selection response (Arnason and Van Vleck, 2000).

So far, the major criterion in the selection program of Lusitano is the mandatory grading of morphology and gaits for registration in the breeders section of the Studbook, including information on nearly 18,000 animals. Nearly three quarters of these records correspond to females, reflecting, to some extent, the conditions imposed by Studbook rules, where all foals to be registered as
Lusitano must be the offspring of sires and dams registered as breeders, which must in turn have been approved in morphology and gaits judgment. As a consequence, there are more females scored, and only those males that the producer intends to use for breeding are submitted to judgment. Notwithstanding, when the census of registered Lusitano sires and dams is considered, the number of approved stallions far exceeds what would be desirable when the number of registered mares is considered, with an observed sex ratio of about 5 breeding females per stallion (Vicente et al., 2012). Thus, it can be anticipated that the resulting selection intensity in the sire path is probably sub-optimal.

Grading of Lusitano horses for morphology and gaits usually occurs at a mean age of over 6 years, because stallions need to be trained for being ridden when they are registered 
in the Studbook. For dressage and working equitation, where the need for training is even more justified, the mean age at competition is about 9 years of age,. As a consequence, the observed generation interval in Lusitano is over 10 years (Vicente et al., 2012), which will certainly restrain long-term selection progress. In other horse breeds, stallions and mares are generally tested and selected at a younger age, ranging from 3 to 6 years old in the Hanoverian, Dutch and Swedish Warmblood, Selle Français and Irish Sports Horse (Thoren Hellsten et al., 2006). Phenotypic trends were moderate over the period of more than 40 years analyzed, with a slight increase observed in HW since the first records were collected up until now (Fig. 1). Minor phenotypic trends over time have also been reported for HW in horse breeds from Brazil (Dornelles et al., 2012) and Croatia (Kaps et al., 2004), probably reflecting the attempt to keep body size approximately stable over time, as it is a trait of major importance in the definition of breed standards and is related with the rideability of a horse. The phenotypic increase in HW found in our study can be attributed essentially to environmental changes, as the genetic trend for HW was nearly null (less than $0.01 \mathrm{~cm} /$ year), and in fact it was the trait where the lowest genetic change in percentage of the mean was observed.

The phenotypic trend for FS was clearly negative, with a decline of about 4.4 points over the period of 40 years considered in our study (Fig. 1), probably reflecting the changes in Studbook rules, with stricter grading thresholds for registration applied in more recent years. This suspicion is confirmed by the positive genetic trend observed for FS (about 0.05 points/year, Table 4), which would imply a negative environmental trend for this trait, as a consequence of progressively more demanding regulations.

The average HW was higher for males by about $3 \mathrm{~cm}$, as could be anticipated given the sexual dimorphism of the horse species (Pinto et al., 2008; Purzyc et al., 2011; Zechner et al., 2001). However, males received lower scores than females for both FS and for the majority of the partial morphological scores. In particular, males were especially penalized in the classification of GA, with a score lower by about 0.5 points when compared with females. This general pattern of lower scores attributed to males probably does not reflect true sex differences, but could be justified by a more strict application of the classification system in sires. In addition, the dynamics of females are usually judged with the animal presented in hand or in liberty, while for stallions it is mandatory that the judgment occurs with the animal ridden by a horseman, and this could justify the strong sex environmental effect observed in GA.

Considerable differences were detected among studs, especially in their environmental effects but also in mean EBV for morphology, gaits and functionality (Fig. 6). For example, the observed variability among studs in mean EBV for FS, HW and functional traits strongly supports the implementation of an organized breeding program, where selection of animals from different studs is a key component. In Lusitano, the exchange of animals among studs has been a common practice, with a few very influential studs (Vicente et al., 2012), which have created strong genetic ties among studs. The availability of breeding values predicted across studs will provide the breeders with objective information which can be used to reinforce selection response.

When a horse is judged in a dressage or working equitation event, it is assigned to a level of competition which reflects the degree of difficulty of the test and the experience of both the horse and the rider. In our analyses of $C D$, the solutions for the level of competition fixed effect indicate that the scores attributed are lower as the level of competition becomes more complex, both at the national and international levels. This is in line with the results reported by Stewart et al. (2010) for dressage results with several horse breeds in Great Britain, and reflects the higher level of difficulty and more stringent judgment usually applied from novice/preliminary levels to more advanced categories (Big Tour).

Inbreeding in horses has been shown to have detrimental effects on racing performance (Klemetsdal, 1998), morphological traits (Gomez et al., 2009; Vostry et al. 2011), reproductive ability (Van Eldik et al., 2006; Sairanen et al., 2009) and increase the incidence of some pathologies (Curik et al., 2000; Sevinga et al., 2004). In our study, inbreeding depression was observed for nearly all the morphological and gait traits analyzed, but its effects on functionality were negligible. For HW, the observed effect of inbreeding was similar to that reported by Vostry et al. (2011) for Czech cold-blooded horses, but much lower than the value reported by Gomez et al. (2009) for the Andalusian horse. For morphological traits, where we estimated negative consequences of inbreeding, there is no clear pattern established for other horse breeds, such that significant inbreeding depression has been reported in some studies (Gomez et al., 2009; Vostry et al., 2011) while other authors have found no appreciable effects of inbreeding (Curik et al., 2003; Sierszchulski et al., 2005; Wolc and Balinska, 2010). Nevertheless, it could be anticipated that the effect of inbreeding on morphological traits would be small, as these are expected to be less affected by inbreeding depression than fitness-related traits (DeRose and Roff, 1999).

The mean level of inbreeding in the Lusitano data set included in our analysis was $10.07 \pm 8.46 \%$, thus covering a wide range of inbreeding levels. Overall, the effect of inbreeding was detrimental for all traits analyzed, even though of very small magnitude. For example, the estimated inbreeding depression expressed relative to the mean of the trait never exceeded $0.1 \%$ of the mean per $1 \%$ inbreeding (Table 3 ), which is far below the estimates of inbreeding depression reported for other species (Burrow, 1993; Lamberson and Thomas, 1984). The low impact of inbreeding depression observed in our study could be a consequence of the slow rate of inbreeding occurred in Lusitano in the past (Vicente et al., 2012), which may have allowed natural and artificial selection to purge some of the negative consequences of inbreeding (Swindell and Bouzat, 2006), or it could just be a specific feature of the horse species, where the consequences of inbreeding seem to be less striking than in other species (Ballou, 1994).

In spite of the moderate heritability estimates reported for FS, GA and WEMT in Lusitano (Vicente et al., 2014), the EBV for these traits show considerable variability (Fig. 5), indicating that selection based on objective 
estimates of genetic merit could be effective. For HW and, to a lesser extent, for WEDT, the heritability is higher, resulting in a wide distribution of EBV, while for $C D$ the much lower phenotypic variability is not compensated by the heritability estimate of 0.32 (Vicente et al., 2014), resulting in a narrow distribution of EBV. For all the traits considered, the dispersion of EBV for selected animals nearly overlaps the distribution for the whole population, indicating that selection differentials have been small, and efforts should be made to incorporate EBV in selection decisions.

When selection was assessed in retrospect, the genetic trend was positive but moderate for all traits analyzed. Comparatively, the highest annual responses expressed in genetic standard deviation units were observed in $\mathrm{HN}, \mathrm{OI}$, GA and FS, while HW has been kept nearly unchanged. As a percentage of the mean, the same traits plus working equitation trials showed the highest responses, but in the best cases the annual genetic trend did not exceed $0.2 \%$ of the mean. The observed responses are in line with the genetic trends reported for conformation traits in Icelandic horses (Albertsdottir et al., 2011), and are somewhat better than those observed in Swedish Warmblood (Arnason, 1987). In our analyses of functional traits, only records collected after 2000 were considered in the analysis of dressage events, and the modest genetic trend achieved is, nevertheless, better than that observed in Selle Français (Dubois and Ricard, 2007), but lower than the results reported for the Swedish Warmblood (Viklund et al., 2011) and for a group of horse breeds competing in dressage events in Great Britain (Stewart et al., 2010). Working equitation is a novel equestrian discipline and, to the best of our knowledge, this is the first time that an Animal Model genetic evaluation is being carried out to analyze it. Our results indicate that, in the period of about 15 years since the beginning of this sports activity the response obtained has been positive but moderate for both WEDT and WEMT. Overall, it is important to emphasize that selection response has been positive for all traits currently considered in the breeding program of Lusitano horses, but the annual response has not exceeded $0.15 \%$ of the mean (Table 4), indicating that there is room for improvement in the selection program. On the other hand, even though they are not explicitly included in the breeding objectives of Lusitano, our results indicate that studs are selecting for functionality, and this has resulted in a slight improvement of WEDT, WEMT and CD.

Genetic selection differentials analyzed in retrospect indicate that, over the years, a higher selection pressure has been applied in sires than in dams. After some fluctuation in the selection differentials in the first decade, they have shown a slightly positive trend over time, especially in males but also in females, indicating that breeders are exercising more care in their selection decisions. The mean genetic selection differentials indicate that, over the last 6 years included in the analyses, the emphasis in male selection has shifted to give more importance to HW, even though FS continues to be the leading trait in relative weight given to conformation and gaits traits. Selection intensity was positive but very modest for all traits analyzed, and increased in the last six years, confirming the efforts made by breeders in selection decisions. Currently, the highest selection emphasis is placed on the total scores reflecting general conformation and grace (FS and OI) and in the key traits reflecting what breeders feel more attractive in the Lusitano horse, such as HN (the distinctive mark of the breed), and BL and GA (as they relate to the ability as a saddle horse). Nevertheless, the realized selection intensity has been very modest, and far below the intensity that could be reached with fewer animals selected, as has been achieved in other horse breeds (Viklund et al., 2011).

As computed in our work, genetic selection differentials reflect the emphasis that studs place directly or indirectly on the various traits, when breeding animals are selected. Notwithstanding, genetic trends are a consequence of both selection differentials, including selection for correlated traits, and of how extensively the selected breeding stallions and mares are used. Therefore, divergences on the relative importance of a specific trait between selection differentials and genetic trends would essentially reflect the extent to which a sire or dam superior for a specific trait has been used for breeding. In our analyses, the major morphological traits selected for and in which higher selection responses were also achieved were OI, HN and GA, confirming that selection and use of breeding animals were consistent for these traits. However, slight discrepancies were found between the selection differentials practiced and realized genetic trends for some traits, as was the case for FS and BL, where genetic selection differentials were important but where responses were minor. For functional traits, both genetic trends (expressed in proportion of the mean) and selection intensity were somewhat higher for WEMT and WEDT than for CD, indicating that studs are putting more emphasis on working equitation.

So far, the Lusitano breeding program has resulted in moderate genetic improvement of conformation, type and gait traits, but some adjustment and refinement can be introduced, in order to optimize selection responses. The formal definition of the breeding objectives is the key element of any genetic improvement program (Van Vleck, 1993), and in the case of Lusitano it is obvious the need to include functionality traits in the breeding goals, while maintaining selection for beauty and type characteristics, which are of paramount importance in Lusitano horses. In particular, traits such as performance in dressage, working equitation and bullfighting ability have received increased attention in the last few years, and should be formally included in the breeding program. The next step is to enhance the use of available information in selection decisions, i.e., to implement a systematic genetic evaluation procedure, allowing the objective and early selection of breeding animals. On the other hand, the breeding program can be further optimized, both by reducing generation intervals (through registration at an earlier age and genetic evaluation of young animals), by enhancing selection accuracy through the use of multivariate Animal Models combining functional and morphological traits, and by increasing selection intensity (by reducing the number of breeding stallions) to levels compatible with an increased selection response. These strategies should be adopted taking into consideration the need to maintain genetic variability, by minimizing inbreeding and avoiding population bottlenecks, as these are primary concerns in the Lusitano horse breed 
(Vicente et al., 2012). The incorporation of genetic markers in selection of Lusitano is a possibility that should be kept in mind, as it is currently being used in selection of sport horses (Haberland et al., 2012; Hill et al., 2010) but, to our knowledge, genomic associations with morphological and beauty traits have not been studied so far.

\section{Conclusions and implications}

Our results indicate that, in spite of the progress being modest, the benefits of selection in Lusitano have been observed mostly in body conformation, type, grace and gaits, confirming the importance that esthetics and equestrian art have historically had in the selection of this breed. Still, enough genetic variability exists for all the traits analyzed, and response to selection could be further improved if a systematic genetic evaluation for the traits considered of interest is adopted in selection decisions.

\section{Conflict of interest statement}

The authors report that there are no conflicts of interest relevant to this publication.

\section{Acknowledgments}

The authors wish to express thanks to Fundação Alter Real, Associação Portuguesa de Criadores do Cavalo PuroSangue Lusitano (APSL) and Federação Equestre Portuguesa (FEP) for providing the data used in this study.

\section{References}

Albertsdottir, E., Eriksson, S., Sigurdsson, A., Arnason, T., 2011. Genetic analysis of "breeding field test status" in Icelandic horses. J. Anim. Breed. Genet. 128, 124-132.

Arnason, T., Van Vleck, L.D., 2000. Genetic improvement of the horse. In: Bowling, A.T., Ruvinsky, A. (Eds.), The Genetics of the Horse, CABI Publishing, Oxon, UK, pp. 473-497.

Arnason, T., 1987. Contribution of various factors to genetic evaluations of stallions. Livest. Prod. Sci. 16 (4), 407-419.

Ballou, J.D., 1994. Population biology. In: Boyd, L., Houpt, K.A. (Eds.) Przewalski's Horse: The History and Biology of an Endangered Species, State University of New York Press, Albany, USA, pp. 93-113.

Boldman, K.G., Kriese, L.A., Van Vleck, L.D., Kachman, S.D., 1995. A Manual for Use of MTDFREML. USDA, ARS.

Bowling, A.T., Ruvinsky, A., 2000. Genetic aspects of domestication, breeds and their origins. In: Bowling, A.T., Ruvinsky, A. (Eds.), The Genetics of the Horse, CABI Publishing, Oxon, UK, pp. 25-52.

Bruns, E., Ricard, A., Koenen, E., 2004. Interstallion - on the way to an international genetic evaluation of sport horses. In: 55th EAAP. Session HG5. Slovenia.

Burrow, H.M., 1993. The effects of inbreeding in beef cattle. Anim. Breed. Abstr. 61, 737-751.

Curik, I., Seltenhammer, M., Sölkner, J., Zechner, P., Bodo, I., Habe, F., Marti, E., Brem, G., 2000. Inbreeding and Melanoma in Lipizzan Horses. Agric. Conspectus Sci. 65 (4), 181-186.

Curik, I., Zechner, P., Sölkner, J., Achmann, R., Bodo, I., Dovc, P., Kavar, T., Marti, E., Brem, G., 2003. Inbreeding, microsatellite heterozygosity, and morphological traits in Lipizzan horses. J. Hered. 94 (2), 125-132.

DeRose, M.A., Roff, D.A., 1999. A comparison of inbreeding depression in life-history and morphological traits in animals. Evolution 53 (4), 1288-1292.

Dornelles, M.A., Araújo, R.O., Everling, D.M., Weber, T., Lopes, J.S., Pacheco, P.S Breda, F.C., Rorato, P.R.N., 2012. Genetic parameters and genetic and phenotypic trends of performance traits of equines from the Brazilian Army. R. Bras. Zootec. 41 (6), 1419-1425.
Dubois, C., Ricard, A., 2007. Efficiency of past selection of the French Sport Horse: Selle Français breed and suggestions for the future. Livest. Sci. 112, 161-171.

Falconer, D.S., MacKay, T.F.C., 1996. Introduction to Quantitative Genetics, 4 th ed. Longmans Green, Essex, UK.

Fioretti, M., Catalano, A.L., Rosati, A., Martuzzi, F., 2005. Bardigiano horse selection: a genetic global index for linear type traits. In: Bodo, I. Alderson, L., Langlois, B. (Eds.), Conservation Genetics of Endangered Horse Breeds, Wagenigen Academic Publishers, The Netherlands, pp. 147-164.

Gaffney, B., Cunningham, E.P., 1988. Estimation of genetic trend in racing performance in thoroughbred horses. Nature 332, 722-724.

Gardner, D.S., 2006. Historical progression of racing performance in thoroughbreds and man. Equine Vet. J. 38 (6), 581-583.

Gomez, M., Valera, M., Molina, A., Gutierrez, J.P., Goyache, F., 2009 Assessment of inbreeding depression for body measurements in Spanish Purebred (Andalusian) horses. Livest. Sci. 122, 149-155.

Gonzaga, P.G., 2004. A History of the Horse: The Iberian Horse from Ice Age to Antiquity. vol. I. J.A. Allen, UK.

Haberland, A.M., König von Borstel, U., Simianer, H., König, S., 2012 Integration of genomic information into sport horse breeding programs for optimization of accuracy of selection. Animal 6, 1369-1376.

Hill, E.W., Gu, J., Eivers, S.S., Fonseca, R.G., McGivney, B.A., Govindarajan, P., Orr, N., Katz, L.M., MacHugh, D., 2010. A sequence polymorphism in MSTN predicts sprinting ability and racing stamina in thoroughbred horses. PLoS ONE 5 (1), e8645, http://dx.doi.org/10.1371/journal. pone.0008645.

Kaps, M., Curik, I., Baban, M., 2004. Modeling variance structure of body shape traits of Lipizzan horses. J. Anim. Sci. 88, 2868-2882.

Klemetsdal, G., 1992. Estimation of genetic trend in racehorse breeding. Acta Agric. Scand. 42 (4), 226-231.

Klemetsdal, G., 1998. The effect of inbreeding on racing performance in Norwegian cold-blooded trotters. Genet. Sel. Evol. 30 (4), 351-366.

Koenen, E.P.C., Aldridge, L.I., Philipsson, J., 2004. An overview of breeding objectives for warmblood sport horses. Livest. Prod. Sci. 88, 77-84.

Lamberson, W.R., Thomas, D.L., 1984. Effects of inbreeding in sheep: a review. Anim. Breed. Abstr. 53, 287-297.

Loch, S., 1986. The Royal Horse of Europe: The Story of the Andalusian and Lusitano. J.A. Allen \& Co Ltd., UK.

Miglior, F., Pagnacco, G., Samore, A.B., 1998. A total merit index for the Italian Haflinger horse using breeding values predicted by a multitrait animal model. In: Proceedings of the 6th WCGALP. XXIV. Armidale, Australia, pp. 416-419.

Mota, M.D.S., Abrahão, A.R., Oliveira, H.N., 2005. Genetic and environmental parameters for racing time at different distances in Brazilian Thoroughbreds. J. Anim. Breed. Genet. 122, 393-399.

Oki, H., Sasaki, Y., 1996. Estimation of genetic trend in racing time of Thoroughbred horse in Japan. Anim. Sci. Technol. Jpn. 67 (2), 120-124.

Olsen, H.F., Klemetsdal, G., Odegard, J., Arnason, T., 2011. Validation of alternative models in genetic evaluation of racing performance in North Swedish and Norwegian cold-blooded trotters. J. Anim. Breed. Genet. 129, 164-170.

Pinto, L.F.B., Almeida, F.Q., Quirino, C.R., Azevedo, P.C.N., Cabral, G.C., Santos, E.M., Corassa, A., 2008. Evaluation of the sexual dimorphism in Mangalarga Marchador horses using discriminant analysis. Livest. Sci. 119, 161-166.

Purzyc, H., Kobrynczuk, F., Bojarski, J., 2011. Sexual dimorphism in Hucul horses using discriminant analysis. Animal 5 (4), 506-511.

Ricard, A., Touvais, M., 2007. Genetic parameters of performance traits in horse endurance races. Livest. Sci. 110, 118-125.

Sairanen, J., Nivola, K., Katila, T., Virtala, A.M., Ojala, M., 2009. Effects of inbreeding and other genetic componentes on equine fertility Animal 3 (12), 1662-1672.

SAS Institute, 2004. SAS ${ }^{\circledR}$ 9.1.2 for Microsoft Windows. SAS International Heidelberg, Germany.

Sevinga, M., Vrijenhoek, T., Hesselink, J., Barkema, H., Groen, A., 2004 Effect of inbreeding on the incidence of retained placenta in Friesian horses. J. Anim. Sci. 82, 982-986.

Sierszchulski, J., Helak, M., Wolc, A., Szwaczkowski, T., Schlote, W., 2005. Inbreeding rate and its effect on three body conformation traits in Arab mares. Anim. Sci. Pap. Rep. 23 (1), 51-59.

Stewart, I.D., Woolliams, J.A., Brotherstone, S., 2010. Genetic evaluation of horses for performance in dressage competitions in Great Britain. Livest. Sci. 128, 36-45.

Swindell, W.R., Bouzat, J.L., 2006. Ancestral inbreeding reduces the magnitude of inbreeding depression in Drosophila Melanogaster Evolution 60 (4), 762-767.

Thoren Hellsten, E., Viklund, A., Koenen, E.P.C., Ricard, A., Bruns, E. Philipsson, J., 2006. Review of genetic parameters estimated at 
stallion and young horse performance tests and their correlations with later results in dressage and show-jumping competition. Livest. Sci. 103, 1-12.

Thoren Hellsten, E., Jorjani, H., Philipsson, J., 2009. Genetic correlations between similar traits in the Danish and Swedish Warmblood sport horse populations. Livest. Sci. 124, 15-20.

Van Eldik, P., Van der Waaij, E.H., Ducro, B., Kooper, A.W., Stout, T.A.E., Colenbrander, B., 2006. Possible negative effects of inbreeding on semen quality in Shetland pony stallions. Theriogenology 65, 1159-1170.

Van Vleck, L.D., 1993. Selection Index and Introduction to Mixed Model Methods. CRC Press, Boca Raton, USA.

Vicente, A.A., Carolino, N., Gama, L.T., 2012. Genetic diversity in the Lusitano horse breed assessed by pedigree analysis. Livest. Sci. 148, $16-25$.

Vicente, A.A., Carolino, N., Ralão-Duarte, J., Gama, L.T., 2014. Selection for morphology, gaits and functional traits in Lusitano horses:
I. Genetic parameters estimate. Livest. Sci. http://dx.doi.org/10.1016/ j.livsci.2014.01.020.

Viklund, A., Nasholm, A., Strandberg, E., Philipsson, J., 2011. Genetic trends for performance of Swedish Warmblood horses. Livest. Sci. $141,113-122$.

Vostry, L., Capkova, Z., Priby, J., Mach, K., 2011. Analysis of Czech coldblooded horses: genetic parameters, breeding value and the influence of inbreeding depression on linear description of conformation and type characters. Czech J. Anim. Sci. 56 (5), 217-230.

Willham, R.L., Wilson, D.E., 1991. Genetic predictions of racing performance in quarter horses. J. Anim. Sci. 69, 3891-3894.

Wolc, A., Balinska, K., 2010. Inbreeding effects on exterior traits in Polish Konik horses. Archiv. Tierz. 53 (1), 1-8.

Zechner, P., Zohman, F., Sölkner, J., Bodo, I., Habe, F., Marti, E., Brem, G., 2001. Morphological description of the Lipizzan horse population. Livest. Prod. Sci. 69, 163-177. 